\title{
Correction to: A Critical Review of Limitations of Slag Capacity Concepts in Metallurgical Applications by Taking Sulfide and Phosphate Capacities as Examples
}

XUE-MIN YANG, JIN-YAN LI, MENG ZHANG, and JIN-SHA JIAO

https://doi.org/10.1007/s11663-021-02137-2

(C) The Minerals, Metals \& Materials Society and ASM International 2021

Correction to: Metallurgical and Materials Transactions B (2021) https://doi.org/10.1007/s11663-020-02045-x

THIS erratum is to correct a defect in Table 1 by removing the additional term [B8] and moving the content up to correct spacing.

The original article has been corrected.
Publisher's Note Springer Nature remains neutral with regard to jurisdictional claims in published maps and institutional affiliations.

A correction to this paper has been published: https://doi.org/10. 1007/s11663-021-02137-2

XUE-MIN YANG is with the CAS Key Laboratory of Green Process and Engineering, Institute of Process Engineering, Chinese Academy of Sciences, Beijing 100190, P.R. China. Contact email: yangxm71@ipe.ac.cn JIN-YAN LI and MENG ZHANG are with Institute of Process Engineering, Chinese Academy of Sciences, Beijing 100190, P.R. China and also with the China Metallurgical Industry Planning and Research Institute, Beijing 100711, P.R. China. JINSHA JIAO is with the Institute of Process Engineering, Chinese Academy of Sciences and also with the Hot Rolling Operation Department, Beijing Shougang Company Limited, Qian'an City, Hebei Province, 064400, P.R. China.

Article published online March 29, 2021. 